\title{
An integrated study on change detection and environment evaluation of surface water
}

\author{
Qiaozhen Guo ${ }^{1} \cdot$ Xiaoxu $\mathrm{Wu}^{2} \cdot$ Xiao Sang $^{1} \cdot$ Ying Fu$^{1} \cdot$ Yuchen $\mathrm{Zang}^{1} \cdot$ Xuemei Gong $^{3}$
}

Received: 17 September 2018 / Accepted: 22 November 2019 / Published online: 5 December 2019

(c) The Author(s) 2019

\begin{abstract}
Surface water pollution is one of the serious environment pollution problems, posing threat to human and other creatures. Extraction, change detection and environment evaluation of surface water are prerequisite for water resource management. Undoubtedly, remote sensing data play an important role in these researches because of its large geographic coverage and high temporal frequency. In this study, the Tianjin Binhai New Area was chosen as the study area and the surface water extraction method Modified Normalized Difference Water Index (MNDWI) was used by combining with adaptive dynamic threshold to extract surface water and detect its change. Comparing with single-band threshold, model of multi-band spectral relationship, Iterative Self-organizing Data Analysis Technique Algorithm and MNDWI, MNDWI-based adaptive dynamic threshold method performed better, which considered the influence of background. Analysis on dynamic change of water showed the area of lake and river had increased and the area of seawater had decreased. Meanwhile, the correlation analysis between area change of surface water and impact factors indicated both climatic and anthropogenic factors made positive contribution to the present water environment situation. Finally, an improved model of surface water environment evaluation was established to evaluate water quality by combining genetic algorithm (GA) and backpropagation (BP) neural network model. And the test results proved that the optimized GA-BP neural network is better than the single BP neural network. The environment evaluation indicated that water quality of the Haihe River section in the study area was poor. Therefore, water environment protection should be strengthened in this area. Some suggestions on practical management were given accordingly.
\end{abstract}

Keywords Surface water $\cdot$ Extraction $\cdot$ Change detection $\cdot$ Environment evaluation $\cdot$ Landsat

Qiaozhen Guo

gqiaozhen@tcu.edu.cn

Xiaoxu Wu

wuxx@bnu.edu.cn

Xiao Sang

sangxiao1993@126.com

Ying Fu

fuying19900707@163.com

Yuchen Zang

m15822289627@163.com

Xuemei Gong

gxmgxm201303@163.com

1 School of Geology and Geomatics, Tianjin Chengjian University, Tianjin 300384, China

2 State Key Laboratory of Remote Sensing Science, College of Global Change and Earth System Science, Beijing Normal University, Beijing 100875, China

3 School of Optics and Photonics, Beijing Institute of Technology, Beijing 100081, China

\section{Introduction}

The investigation and research on surface water resources have always been a hot topic, since it is a key to social, ecological, healthy and economic developments (Sun et al. 2012). Meanwhile, quality evaluation of water environment becomes more and more important (Meng et al. 2015; Perrin et al. 2014; An et al. 2014). Accurate water environment evaluation can not only reveal water pollution situation, but also provide scientific basis for decision-making in water pollution control.

Surface water information extraction is the prerequisite for surface water resources investigating and environment monitoring. There are two types of data sources, i.e., the traditional field survey data and remote sensing data. The former tends to be limited in terms of spatial coverage and temporal resolution (Palmer et al. 2015). Therefore, remote sensing data have become primary sources extensively used for extracting surface water and detecting its changes 
(Rokni et al. 2014; Li et al. 2013), with the advantages of large observation range, high speed, strong timeliness, rich information, precise measurement and low costs (McFeeters 2013; Bukata 2013). There are numerous remote sensing satellite images used for extracting surface water. Among them, Landsat imagery is one of the most widely used data in extracting surface water information, due to its moderate spectral resolution and sensitive response to surface water.

Surface water extraction can be realized through many methods, including single-band threshold method, multiband spectral relationship method, Iterative Self-organizing Data Analysis Technique Algorithm (ISODATA) and water index method. Most of the above-mentioned surface water extraction methods consider the extraction model as integral and simple, which works well for large-area waters. Nevertheless, there usually exists a transition section between small-area surface waters and other land-use types, where it is difficult to automatically determine the threshold for the small-area waters since only one threshold is used for each land-use type. Therefore, a method, which is able to determine the threshold for all types of waters, is a key to extracting surface water accurately. In this study, a MNDWI-based adaptive dynamic threshold method of surface water extraction was proposed, which combined advantage of MNDWI in removing shadow from waters and determining threshold for all types of waters. And then, a preliminary correlation analysis was done between surface water area change and climatic as well as human factors.

For the evaluation of surface water quality, chlorophyll-a and suspended matter are important parameters that characterize water quality (Nechad et al. 2010). Remote sensing technology can monitor the spatial and temporal changes of water quality parameters effectively within a certain period, which is very suitable for large-scale monitoring of water bodies. Chen et al. (2013) improved three-band semi-analytical algorithm which was used to monitor chlorophyll-a in Yellow River estuary. Park et al. (2015) predicted chlorophyll-a concentration for the early warning in the Juam Reservoir and Yeongsan Reservoir used artificial neural network and support vector machine (SVM); meanwhile, SVM model showed better. Chow et al. (2016) analyzed water quality data of the Feitsui Reservoir basin by different multivariate statistical techniques. Essam et al. (2017) developed a remote sensing framework based on the backpropagation (BP) neural network which described relationship between surface water quality parameters and satellite. And the used self-learning ability is suitable for surface water environment evaluation, but it still has some imperfections, such as local extremum and randomness of initial weights and thresholds. Therefore, an optimized model is needed for water environment evaluation. In this study, based on field survey data on water quality parameters, and using genetic algorithm (GA) to optimize BP neural network, multifactor water environment evaluation model was built to evaluate water quality. And based on GIS technology, the evaluation results were visualized, so as to provide accurate, reliable and intuitive technical support for protecting and improving regional water environment.

\section{Materials and methods}

\section{Study area}

The Tianjin Binhai New Area is located in the east of Tianjin and the northeast of North China Plain, covering latitude of $38^{\circ} 40^{\prime} \mathrm{N}-39^{\circ} 00^{\prime} \mathrm{N}$ and longitude of $117^{\circ} 20^{\prime} \mathrm{E}-118^{\circ} 00^{\prime} \mathrm{E}$. Its surface belongs to alluvial plain, with main geomorphic types including strand plain, lagoons and beach. Climate change in four seasons is distinct: high temperature, high humidity and much rain in summer; coldness and snowless weather in winter; warmness in autumn; and drought and windy weather in spring. The Tianjin Binhai New Area covers all lands of the three administrative regions (Tanggu District, Hangu District and Dagang District) and part land of the two administrative regions (Dongli District and Jinnan District). Haihe River, Jiyunhe River, Chaobai River, Duliujian River and other major rivers all flow into the Bohai Sea through the district of Tianjin. The surface water is large in area and low flat in relief. Geographic location of the study area is shown in Fig. 1 which is derived from the OLI true color image acquired in April 22, 2014.

In the study area, there are 8 rivers with flood discharge meeting the first level, 22 drainage channels with flood discharge meeting the second level, 1 large reservoir, 7 medium-sized reservoirs and 23 small reservoirs. Among them, the Beidagang Reservoir built in 1974 is the largest plain reservoir in North China, and it occupies $164 \mathrm{~km}^{2}$. Ecological resources of waters are very rich in the study area.

The Tianjin Binhai New Area is one of the most rapidly developed regions in China during the past decades. Its rapid socioeconomic development has a heavy demand for water resources; thus, it is of great significance to thoroughly study surface water in the region. Poor condition of surface water, combined with non-compliance emissions of industrial and domestic wastewater, worsened water pollution and destructed the ecosystem within Tianjin. So water resources are relatively scarce and the problem of water environment is very serious in Tianjin.

\section{Data source}

Data used in this study include remote sensing images and basic geographic data such as administrative boundary map, meteorological data, socioeconomic data and field 


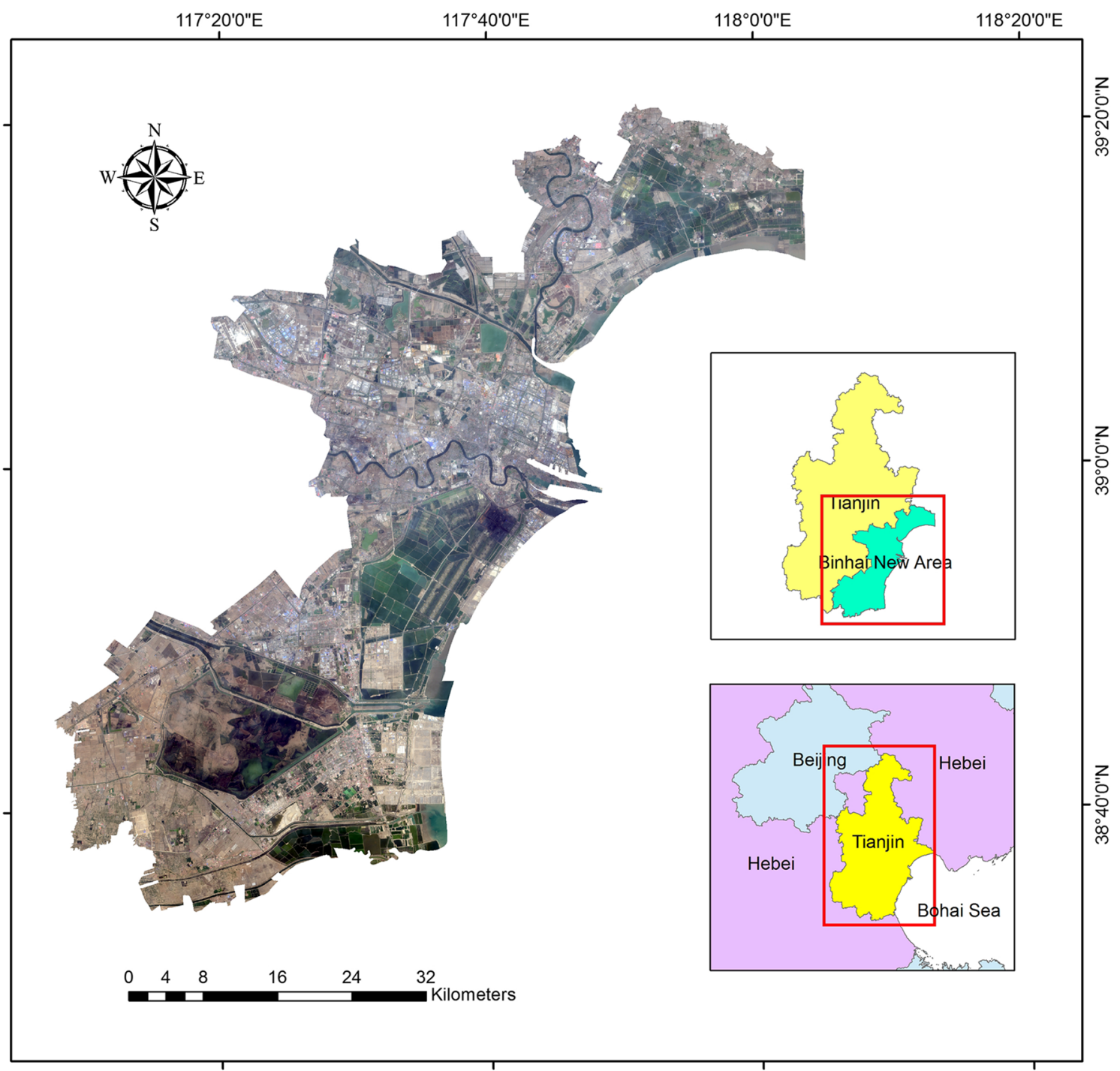

Fig. 1 Location of the study area

survey data. Remote sensing images include five scenes of Landsat TM images with spatial resolution of $30 \mathrm{~m}$, respectively, in 1985, 1990, 1995, 2005 and 2010, one scene of ETM + image with spatial resolution of $15 \mathrm{~m}$ in 2000 , and one scene of OLI image with spatial resolution of $15 \mathrm{~m}$ in 2014. Landsat images were acquired from the US Geological Survey (USGS) Global Visualization View and all free of clouds. Meteorological data include average annual temperature and precipitation data collected from the Tanggu meteorological station in the Tianjin Binhai New Area. The socioeconomic data include population and GDP data obtained from the statistical yearbook of the Tianjin Binhai New Area.

Field survey data were collected on April 22, 2014, from water sampling points along the Haihe River. Water quality parameters were extracted based on collected water samplings, including $\mathrm{pH}$ value, oxidation-reduction potential
(ORP), total dissolved solids (TDS), suspended matter, dissolved oxygen, conductivity, chlorophyll-a, transparency, water temperature and physical state. Values of $\mathrm{pH}$, ORP, TDS, dissolved oxygen and conductivity were measured in filed using water quality instrument. Chlorophyll-a concentration was measured using the spectrophotometric method when water samples were taken back to the laboratory. Suspended matter was obtained using the membrane method based on the Specification of Oceanographic Survey (GB 17378.4-2007). Transparency was derived based on data conversion table between suspended matter and transparency of water. The input data were the suspended matter, and the output data were the corresponding transparency. Water environment evaluation was conducted with reference to the national surface water environment quality standards (GB3838-2002). Evaluation factors included dissolved oxygen, chlorophyll-a and transparency. The unqualified 
sampling points were eliminated, and finally, 21 sampling points were left, i.e., a $3 \times 21$ matrix.

\section{Methods}

\section{Data processing}

The data preprocessing included atmospheric correction, geometric correction and resampling. Atmospheric correction was applied to seven scenes of images using the Fast Line-of-Sight Atmospheric Analysis of Spectral Hypercubes module. A binary quadratic polynomial was used to do geometric correction with six control points and two check points selected. And the images were georeferenced with a root mean square error less than 0.5 pixels. Then, the images of the Tianjin Binhai New Area from 1985 to 2014 were cut out by the boundary. The projection was defined as UTM zone 50 North using WGS-84 datum for all images. The data were resampled to the same size using the nearest neighbor method.

\section{Water extraction}

In order to analyze spectral luminance feature of water and other land use types, land use classification was conducted according to the current land use classification national standard (GB/T 201010-2017), regional characteristics of the Tianjin and the study purposes. In this study, land use was divided into five types: lake, river, salt evaporation pond, seawater and land. The lake refers to natural lake and artificial reservoir. The river refers to natural river, ditches and artificial river. The salt evaporation pond refers to the place where salt is extracted by evaporation. The seawater refers to water in the sea or from the sea. The land refers to land use type other than the above-mentioned. Using MNDWI method in combination with adaptive dynamic threshold, the study area was divided into these land use types. A sample was selected for each land use type in remote sensing images, and spectrum reflectance of each band was determined. The reflectance of water is stronger in the range of 450-600 $\mathrm{nm}$, but spectrum contrast is not obvious for other land use types. The average reflectance of each land use type was obtained by statistics.

Water is generally divided into linear structure and area structure in the remote sensing images. For example, rivers, ditches and continuous bead rivers belong to linear waters, while lakes and ponds belong to area waters. Although rivers, lakes and salt evaporation ponds are all filled with water, the morphological characteristics of them are different in remote sensing images. Salt evaporation pond is composed of many fields with square shape. Lake is generally smaller in area and its distribution is more scattered. River usually shows a regularly long strip shape.
The dynamic threshold affects accuracy of surface water extraction directly. MNDWI was a formula proposed by Xu (2006) used to extract water and was defined as the quotient of the difference and sum between reflectance of the visible light channel and mid-infrared channel. For the Landsat OLI image, the visible light channel corresponds to band 3 and the mid-infrared channel corresponds to band 6, and therefore, its MNDWI was derived according to Eq. (1).

MNDWI $=($ Band $3-$ Band 6$) /($ Band $3+$ Band 6$)$

The proposed water extraction method applied MNDWI method in combination with adaptive dynamic threshold. This method considers local information with adaptive dynamic threshold. Using the local context information, it can eliminate false change information effectively. To apply this new method, the MNDWI was calculated from the images. Then we separated water from background using segmentation method and selected the appropriate training samples, and finally, end elements were gotten. The pixels within the whole image have different segmentation threshold values, and local features of pixels were also taken into account. Finally, each type of surface water was extracted from images according to 5 shape features.

\section{Surface water environment evaluation based on GA-BP model}

The GA-BP model was used to evaluate surface water environment. First, network parameters were determined. The network input layer included three node data, namely chlorophyll-a, transparency and dissolved oxygen data. The output layer was one layer that was ultimate evaluation result of water quality. Hidden layer included the number of hidden layer nodes after processed by tansig function. Output layer included the number of output nodes after processed by purelin function. Figure 2 shows the structure of BP neural network. Second, the weight and threshold of BP neural network were intervened by GA. The first step was initialization. Using initialization function, the whole network was initially set. After initialization, weight and threshold values of BP neural network began to enter selection process of GA. The evolutionary process was accomplished using distributed population, combined with the appropriate selection operator, crossover operator and mutation operator. The choice of operators was mainly determined by the comparison of test results, followed by the parameters needed for the data call. In this study, normGeomSelect was chosen as the selection operator, arithXover as the crossover operator and nonUnifMutation as the mutation operator. After evolution, the system entered evaluation phase. According to the evaluation function and the difference of system output, whether the weight and threshold values meet the required 


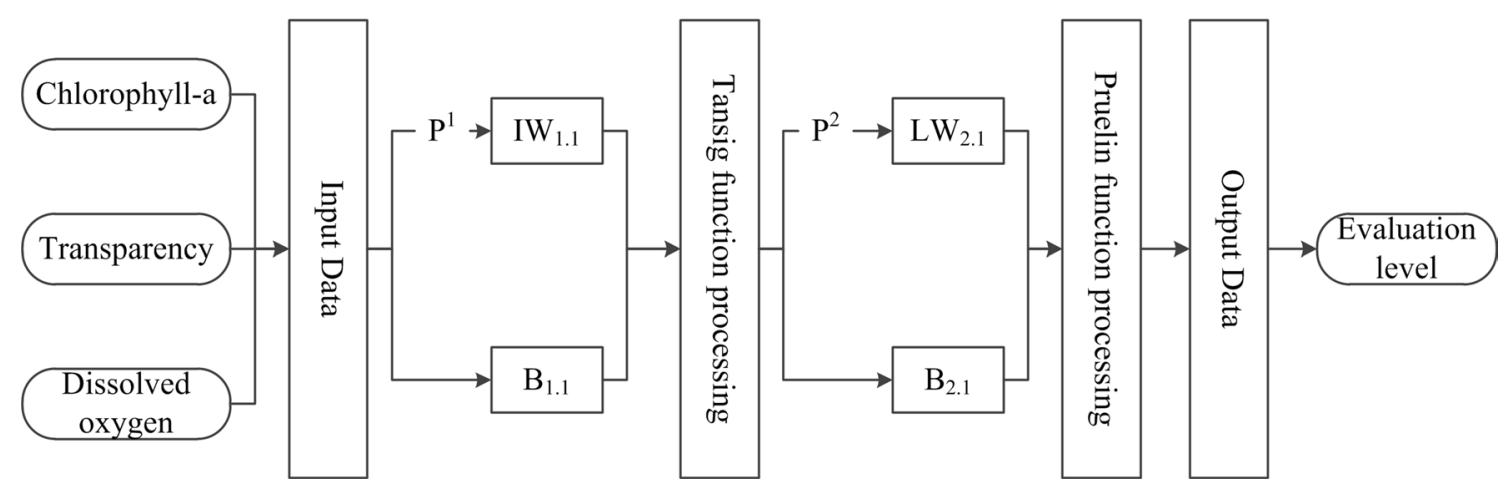

Fig. 2 Structure of BP neural network ( $\mathrm{P}$ is the source data; IW is the weight from input layer to hidden layer; LW is the weight from hidden layer to output layer; $\mathrm{B}$ is the threshold from input layer to hidden layer; $\mathrm{B}_{2.1}$ is the threshold from hidden layer to output layer)

accuracy was evaluated. If it does not meet, the optimization process of GA was repeated. If it meets, the optimized weights and thresholds of BP neural network were output into the original network; thus, the optimization of BP neural network was completed with GA. Figure 3 shows the running process of basic training parameters based on GA-BP neural network. Third, training of BP neural network was conducted by using the assigned weight and threshold values. After the weight and threshold were intervened with GA, system would transmit new weight and threshold to BP neural network according to codec function, and then, they were trained with BP neural network again. Updated weight and threshold were assigned to corresponding part of the neural network. The process of training was implemented in MATLAB. The test data were part of field survey data.

After GA-BP neural network training, output results were stored and should not be an integer. Numerical estimation values using common methods were relatively rough when the numerical data were centered. It was likely to reduce accuracy in water quality assessment. So in this study, the method of interval taking value was used to determine water quality grade (Table 1).

\section{Results}

\section{Dynamic change of surface water}

Due to diversity and complexity of local surface water, the study area was partitioned. Surface water extraction results using MNDWI-based adaptive dynamic threshold method during 1985-2014 are shown in Fig. 4. The classification accuracy was evaluated using visual interpretation based on high-resolution images from Google Earth. The accuracy evaluation of surface water extraction results is shown in Table 2. The overall accuracy was above $95 \%$, and the kappa coefficients were above 0.9100. Thus, the classification results can satisfy the requirements of the accuracy.

Based on the remote sensing interpretation results of land use in seven periods, change of land use in the Tianjin Binhai New Area is shown in Table 3. Area of salt evaporation pond and seawater showed a decreasing trend in this area for nearly 30 years. The seawater area had decreased most by $90.69 \mathrm{~km}^{2}$. Area of salt evaporation pond had reduced by $57.92 \mathrm{~km}^{2}$. Lake area had increased most by $187.40 \mathrm{~km}^{2}$. River area also had increased by $12.56 \mathrm{~km}^{2}$. Area of land also had decreased by $51.35 \mathrm{~km}^{2}$. From 1985 to 2014 , lake area changed greatest and showed an instable trend as a whole; river area increased as a whole and it reached the highest value of $70.99 \mathrm{~km}^{2}$ occupying $2.80 \%$ of the whole study area in 1990; area of salt evaporation pond reached the highest value of $410.42 \mathrm{~km}^{2}$ in 1990 , accounting for $16.20 \%$ of the whole study area; seawater area reached the highest value of $160.55 \mathrm{~km}^{2}$ in 1990 , accounting for $6.34 \%$ of the whole study area. From 1985 to 1990 , area and proportion of all types of surface waters had increased. Among them, lake area had increased greatest by $61.48 \mathrm{~km}^{2}$ and its proportion also rose from $6.51 \%$ to $8.93 \%$. From 1990 to 1995 , area of lake and land had increased, and the most significant decrease occured for the area of salt evaporation pond and its proportion had decreased by $1.95 \%$. From 1995 to 2000, area of salt evaporation pond and land had increased; lake area reduced most and its proportion had decreased by $1.10 \%$. From 2000 to 2005, area of lake and salt evaporation pond had increased; lake area had increased most and its proportion had increased by $2.88 \%$. From 2005 to 2010 , only land area had increased; area of other surface waters had reduced, and lake area had reduced most and its proportion had decreased by $2.13 \%$. From 2010 to 2014, area of lake and river had increased, while it for other land use types had decreased. 


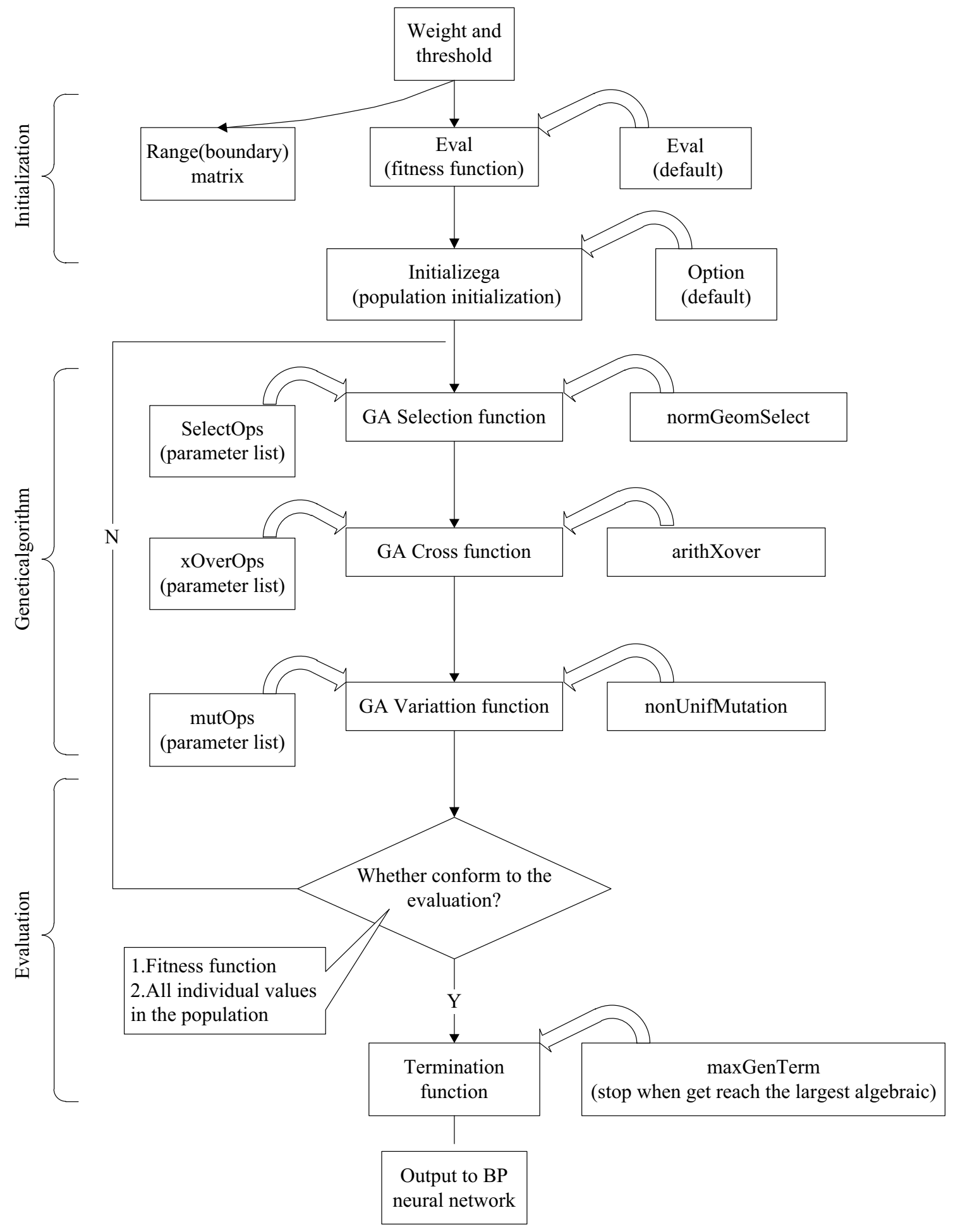

Fig. 3 Running process chart of basic training parameters based on GA-BP neural network

\section{Impact factors for surface water change}

Dynamic change of surface water is related to climatic and human factors. Influential climatic factors include temperature, precipitation, evaporation and others, but this study only focused on temperature and precipitation. Human factors mainly include population and economic growth.

The study area features warm temperate semi-humid continental climate and is affected by monsoon circulation greatly from the Bohai Sea. The yearly average temperature 
Table 1 Water quality grade and corresponding output value

\begin{tabular}{ll}
\hline $\begin{array}{l}\text { Water quality } \\
\text { grade }\end{array}$ & Output value \\
\hline I & $0.5-1.5$ \\
II & $1.5-2.5$ \\
III & $2.5-3.5$ \\
IV & $3.5-4.5$ \\
V & $>4.5$ \\
\hline
\end{tabular}

and precipitation during 1985-2014 are shown in Fig. 5. The increasing trend of temperature was obvious, and the temperature was increased by $3.0{ }^{\circ} \mathrm{C}$ during nearly 30 years. However, the yearly average precipitation showed a decreasing trend during the whole period. It rained more in the late 1980s and decreased significantly in 1990s. The precipitation only showed increasing trend in two periods, respectively, from 2002-2005 to 2008-2012.

The correlation analysis between the yearly average precipitation, yearly average temperature and water area from 1985 to 2014 was done. The results showed that a threepolynomial correlation exists between these three variables (Eq. 2).

$y=-0.24964 \times x_{1}+55.5353 \times x_{2}+0.01256 \times x_{1} \times x_{2}-345.87173$

where $y$ denotes the area of freshwaters including river and lake, $x_{1}$ denotes the yearly average precipitation and $x_{2}$ denotes the yearly average temperature. The coefficient of determination was 0.9093 , which indicated strong correlation existed between them. An increase in temperature led to increase in freshwater area. However, precipitation had a more complicated impact on water area.

The correlation between population size and all water area in the study area was analyzed. According to the statistics, the total population increased from 81.59 million in 1985 to 289.43 million in 2014 , increasing by 3.55 times. As a nation-level New Area, the Tianjin Binhai New Area was developing rapidly and its gross domestic product (GDP) had been growing. The GDP was 24.164 billion RMB in 1995 and 876.015 billion RMB in 2014, increasing by 35.25 times. With economic development, utilization demand of surface water also increased. However, protection and management of water environment had also been strengthened by local government. Therefore, utilizing seawater and protecting freshwater became an effective measure. Accordingly, area of lake and river had been increased and area of salt evaporation pond and seawater had been decreased during 1995-2014.

Based on the above analysis, surface water change was driven by both climatic and human factors. From climatic perspective, freshwater area increased with increasing temperature; thus, climate change favored increase in freshwater area. From human perspective, increasing population and economic growth brought a decrease in seawater area; meanwhile, local government's protection and management of water environment led to no decrease in area of freshwater. Therefore, we can conclude that dynamic change of surface water in the study area mainly due to positive effect of climate change and national use and protection of water resources by local government.

\section{Surface water environment evaluation}

\section{Water quality evaluation}

According to surface water environment evaluation method and the test output results of GA-BP neural network, water quality of 21 sampling points was determined as shown in Table 4. According to the grade evaluation of water quality, water of the Haihe River section in the study area was polluted severely. Grades of water quality among 21 sampling points were as follows: no sampling points for Grade I; 6 for Grade II; 8 for Grade III; 6 for Grade IV; and 1 for Grade V. Grade II water quality indicated that water had been polluted slightly. Grade III water quality indicated that water had been polluted moderately. And chemical content of Grade III water was several times more than that of Grade II water. It is polluted water when water quality is below Grade III, and this type of water is generally used as industrial as well as agricultural water or as the landscape water, with which human usually has non-direct contact. In this study, water quality of a third of sampling points was below Grade III. This indicated that water quality of the whole study area was not good, and most of waters were seriously polluted, which was also related to a rapid development of the Tianjin Binhai New Area in recent years.

\section{Visualizing distribution of water environment}

Based on the grade of evaluation results, water quality in the study area was visually displayed using GIS visualization technology. Evaluation grade of 21 sampling points was used as input data, and interpolation was realized using Kriging interpolation method. Figure 6 shows a partial enlargement map using spherical model of ordinary Kriging interpolation for the water quality sampling points.

Clearly, the sampling area was most seriously polluted in the Haihe River section from Jiajiatai to Liuzhuang. Water quality was mainly of Grade IV and Grade V in this part of river, indicating water was under heavy pollution. There were mainly residential and industrial lands from Jiajiatai to Liuzhuang; thus, water pollution there led to continuous deterioration of surrounding ecological environment. For the river section from Luzui to Hujiayuan, water quality was mainly of Grade III, which indicated

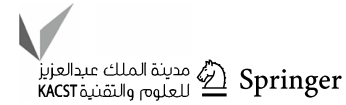




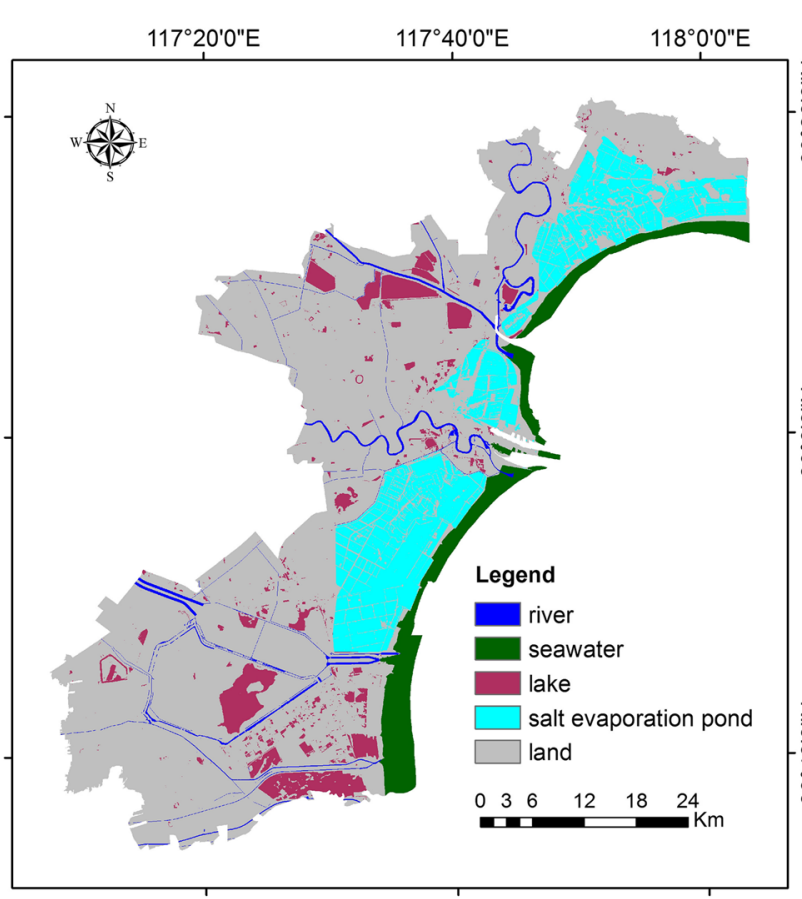

(a)

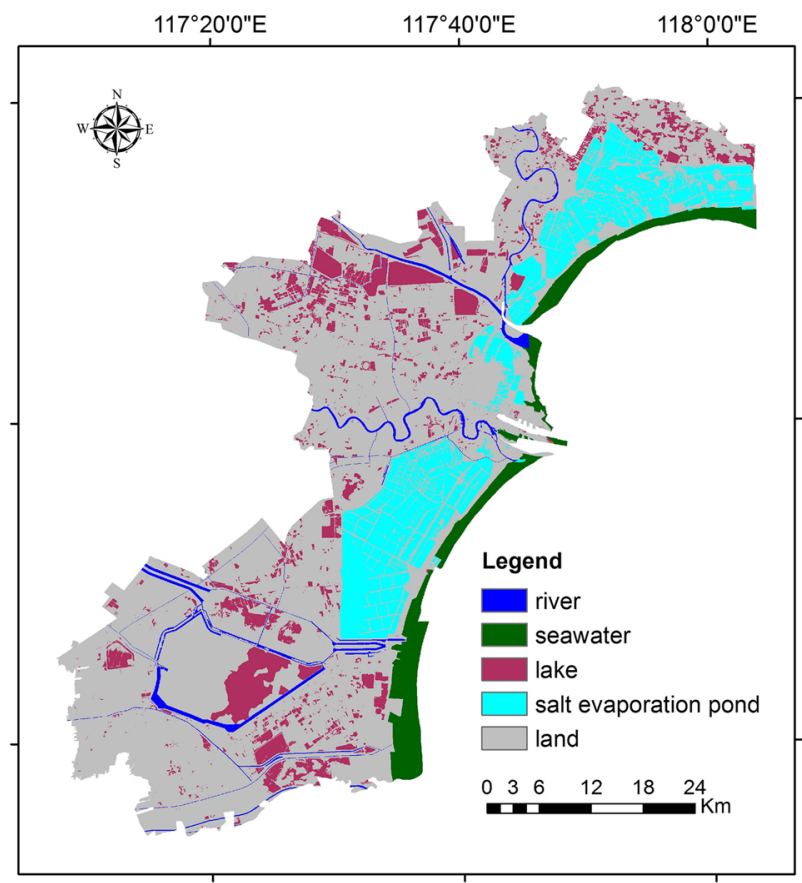

(c)

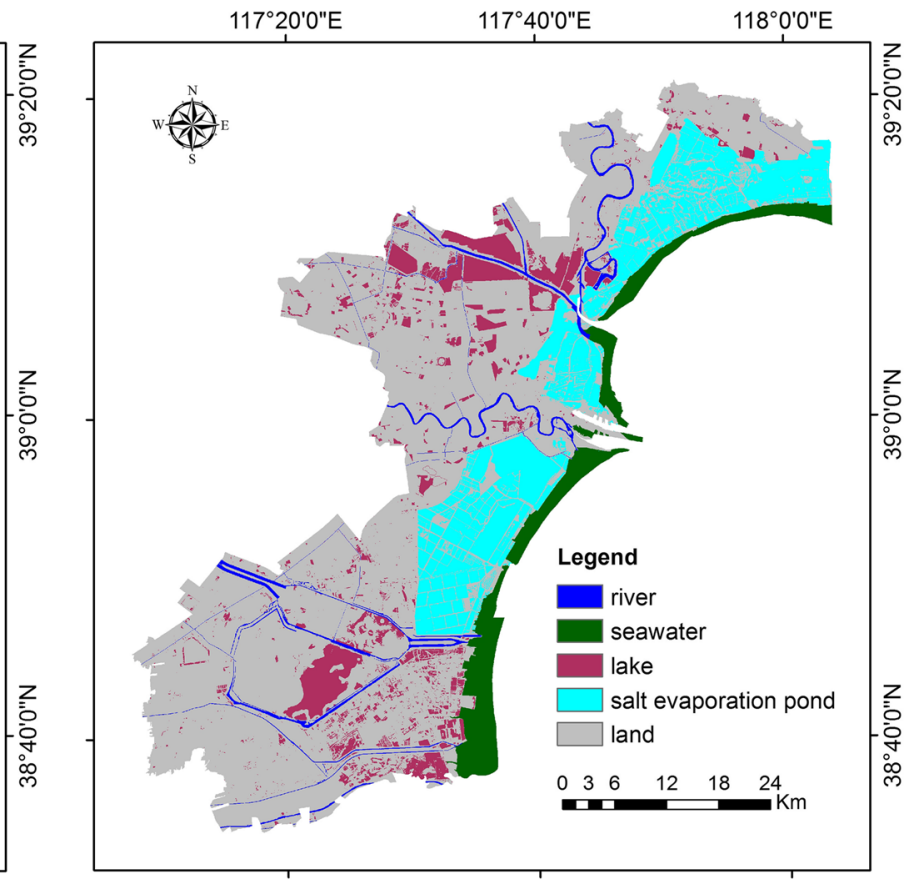

(b)

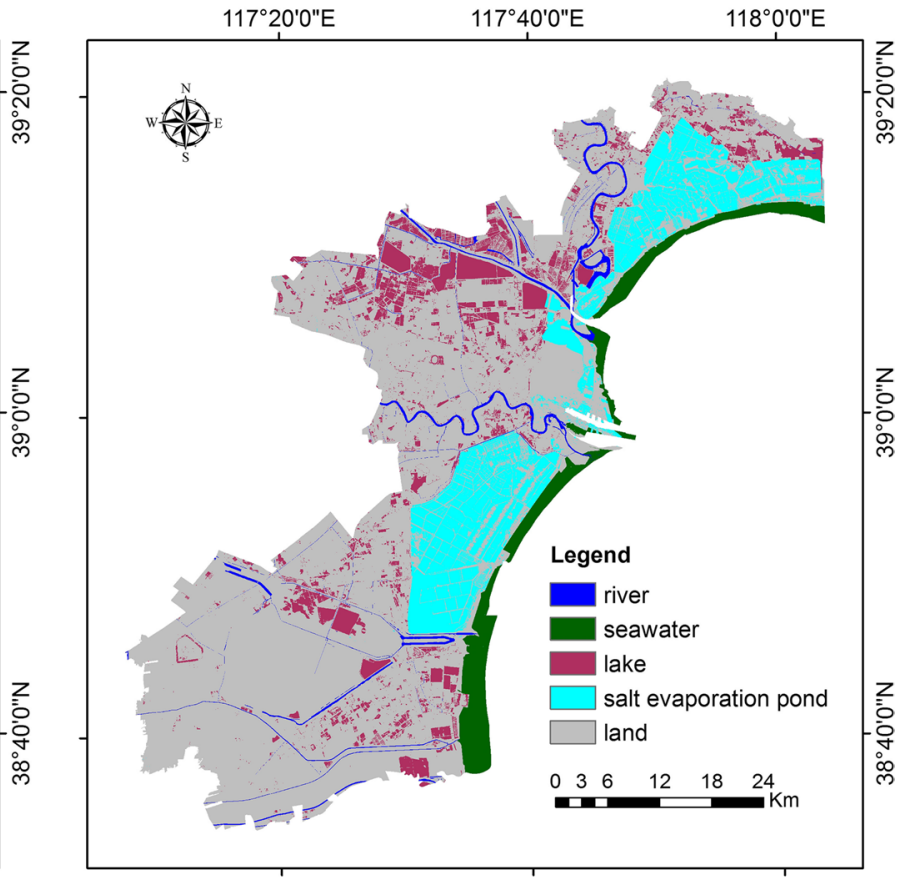

(d)

Fig. 4 Maps of surface water extraction using MNDWI-based adaptive dynamic threshold method: a 1985; b 1990; c 1995; d 2000; e 2005; f 2010; g 2014; h location

that water pollution there was more serious. The sewage of residents, combined with such pollutants as dirt and chemicals resulted from urban expansion, rendered water pollution to become more serious in the river section from
Luzui to Hujiayuan. For the Tianjin Binhai New Area, water with Grade I quality seldom existed, and distribution of areas with Grade II water quality was too rare to cluster. The reason lies in that water was polluted in the 


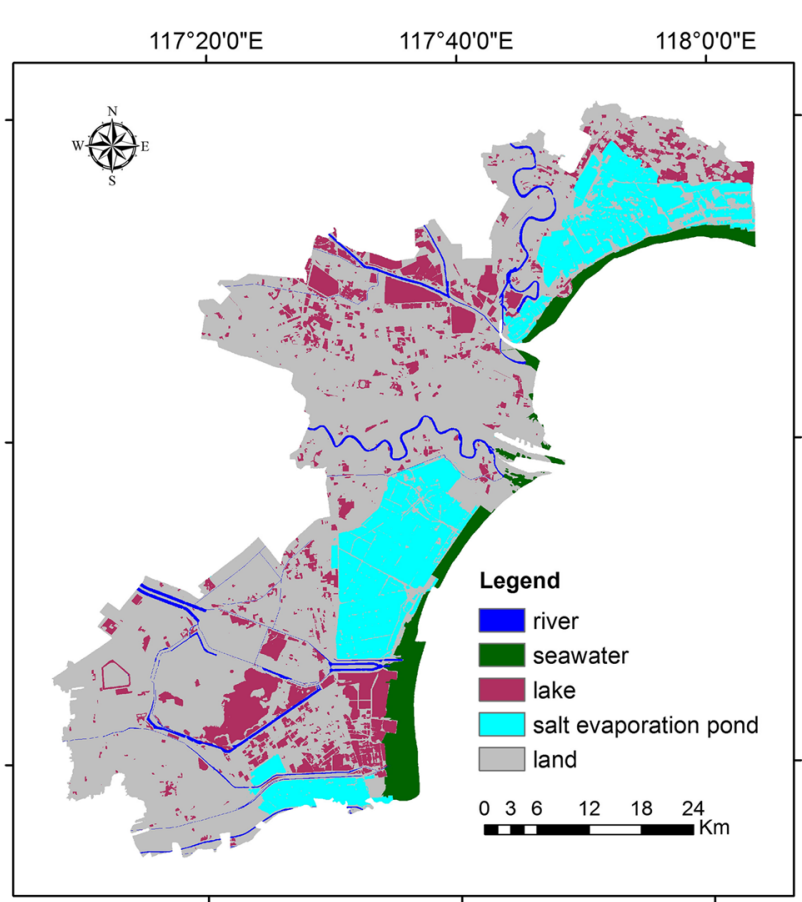

(e)

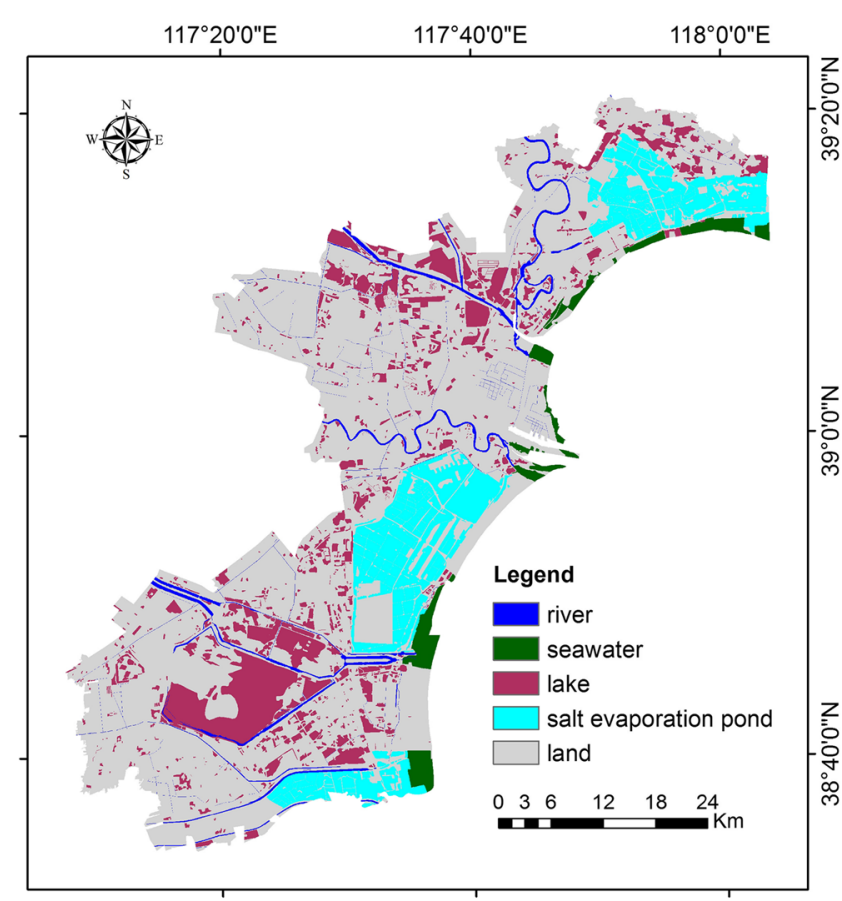

(g)

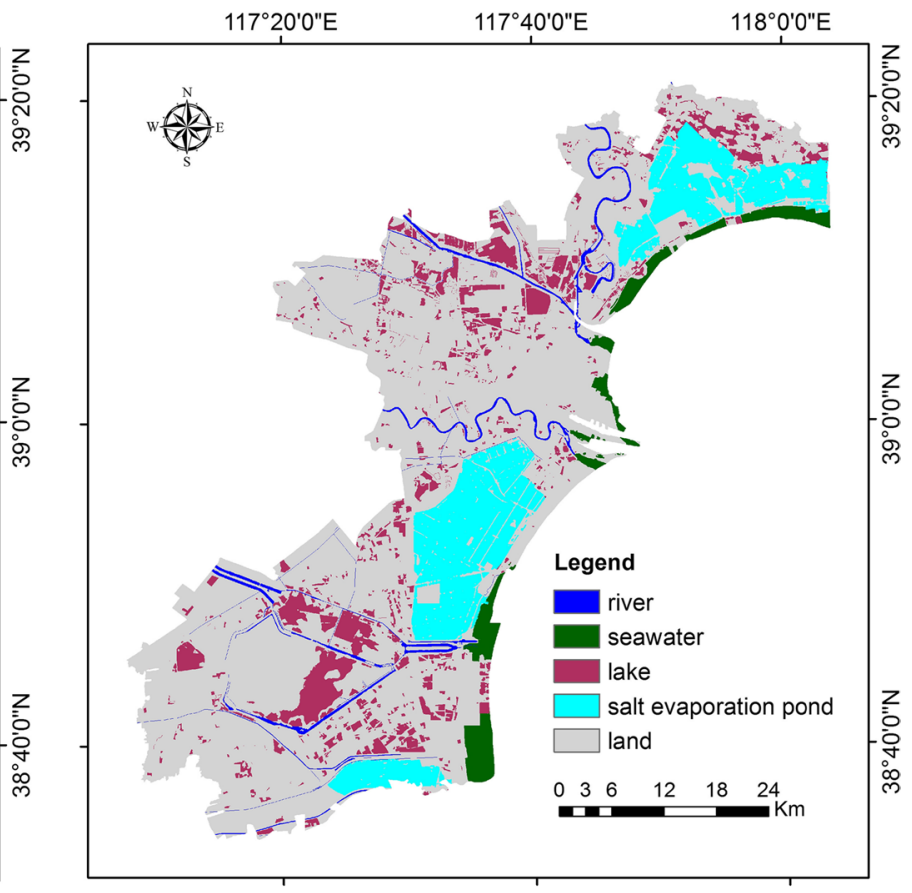

(f)

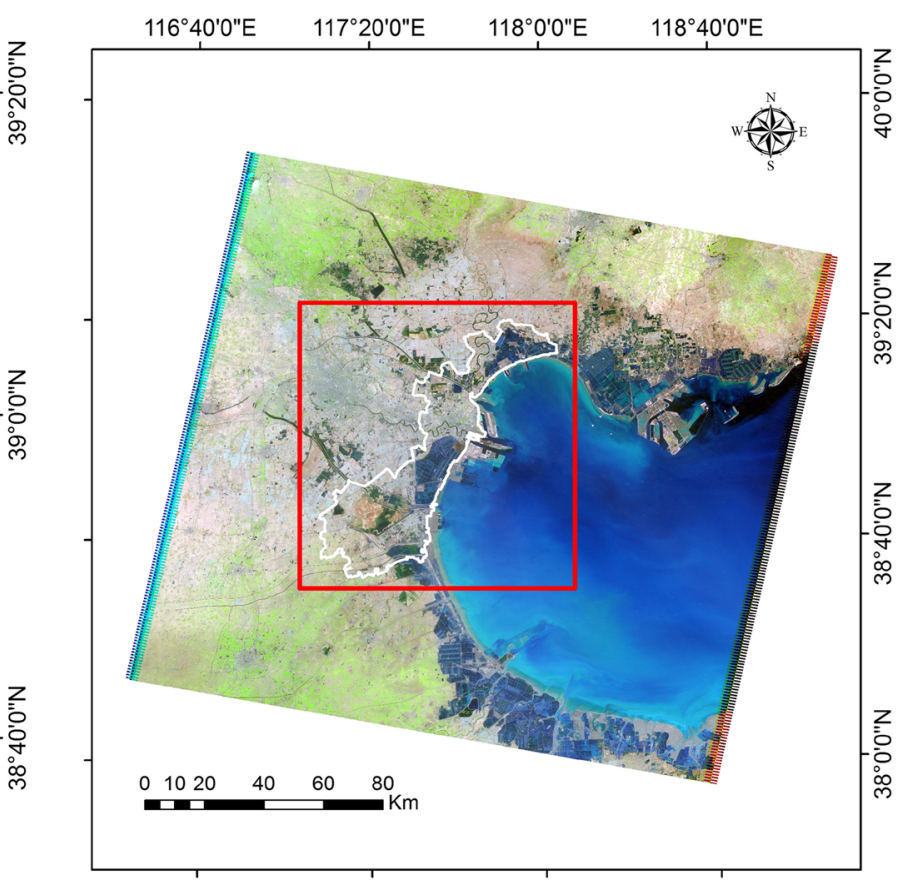

(h)

Fig. 4 (continued)

Table 2 Overall accuracy and kappa coefficients of surface water extraction results during 1985-2014

\begin{tabular}{|c|c|c|c|c|c|c|c|}
\hline Year & 1985 & 1990 & 1995 & 2000 & 2005 & 2010 & 2014 \\
\hline Overall accuracy & $97.31 \%$ & $95.38 \%$ & $97.31 \%$ & $97.69 \%$ & $96.54 \%$ & $97.31 \%$ & $98.00 \%$ \\
\hline Kappa coefficient & 0.9505 & 0.9100 & 0.9411 & 0.9503 & 0.9307 & 0.9437 & 0.9539 \\
\hline
\end{tabular}


Table 3 Land-use change in the Tianjin Binhai New Area during 1985-2014

\begin{tabular}{|c|c|c|c|c|c|c|}
\hline Index & Year & Lake & River & $\begin{array}{l}\text { Salt evapora- } \\
\text { tion pond }\end{array}$ & Seawater & Land \\
\hline \multirow[t]{7}{*}{ Area $/ \mathrm{km}^{2}$} & 1985 & 164.81 & 58.12 & 383.60 & 157.14 & 1770.03 \\
\hline & 1990 & 226.29 & 70.99 & 410.42 & 160.55 & 1665.45 \\
\hline & 1995 & 275.88 & 66.45 & 361.15 & 133.84 & 1696.38 \\
\hline & 2000 & 248.02 & 61.34 & 375.28 & 128.60 & 1720.46 \\
\hline & 2005 & 321.02 & 61.26 & 397.93 & 123.93 & 1629.56 \\
\hline & 2010 & 267.14 & 58.74 & 353.61 & 83.69 & 1770.52 \\
\hline & 2014 & 352.21 & 70.68 & 325.68 & 66.45 & 1718.68 \\
\hline \multirow[t]{7}{*}{ Proportion of area/\% } & 1985 & 6.51 & 2.29 & 15.14 & 6.20 & 69.86 \\
\hline & 1990 & 8.93 & 2.80 & 16.20 & 6.34 & 65.73 \\
\hline & 1995 & 10.89 & 2.62 & 14.25 & 5.28 & 66.95 \\
\hline & 2000 & 9.79 & 2.42 & 14.81 & 5.08 & 67.90 \\
\hline & 2005 & 12.67 & 2.42 & 15.71 & 4.89 & 64.32 \\
\hline & 2010 & 10.54 & 2.32 & 13.96 & 3.30 & 69.88 \\
\hline & 2014 & 13.90 & 2.79 & 12.86 & 2.62 & 67.83 \\
\hline \multirow[t]{6}{*}{ Variation $/ \mathrm{km}^{2}$} & 1985-1990 & 61.48 & 12.87 & 26.82 & 3.41 & -104.58 \\
\hline & 1990-1995 & 49.59 & -4.54 & -49.27 & -26.71 & 30.93 \\
\hline & $1995-2000$ & -27.86 & -5.11 & 14.13 & -5.24 & 24.08 \\
\hline & $2000-2005$ & 73 & -0.08 & 22.65 & -4.67 & -90.9 \\
\hline & 2005-2010 & -53.88 & -2.52 & -44.32 & -40.24 & 140.96 \\
\hline & 2010-2014 & 85.07 & 11.94 & -27.93 & -17.24 & -51.84 \\
\hline \multirow[t]{6}{*}{ Proportion of variation $/ \%$} & 1985-1990 & 2.42 & 0.51 & 1.06 & 0.14 & -4.13 \\
\hline & 1990-1995 & 1.96 & -0.18 & -1.95 & -1.06 & 1.22 \\
\hline & $1995-2000$ & -1.10 & -0.20 & 0.56 & -0.20 & 0.95 \\
\hline & $2000-2005$ & 2.88 & 0.00 & 0.90 & -0.19 & -3.58 \\
\hline & 2005-2010 & -2.13 & -0.10 & -1.75 & -1.59 & 5.56 \\
\hline & 2010-2014 & 3.36 & 0.47 & -1.1 & -0.68 & -2.05 \\
\hline
\end{tabular}

Fig. 5 Variation of temperature and precipitation in the study area

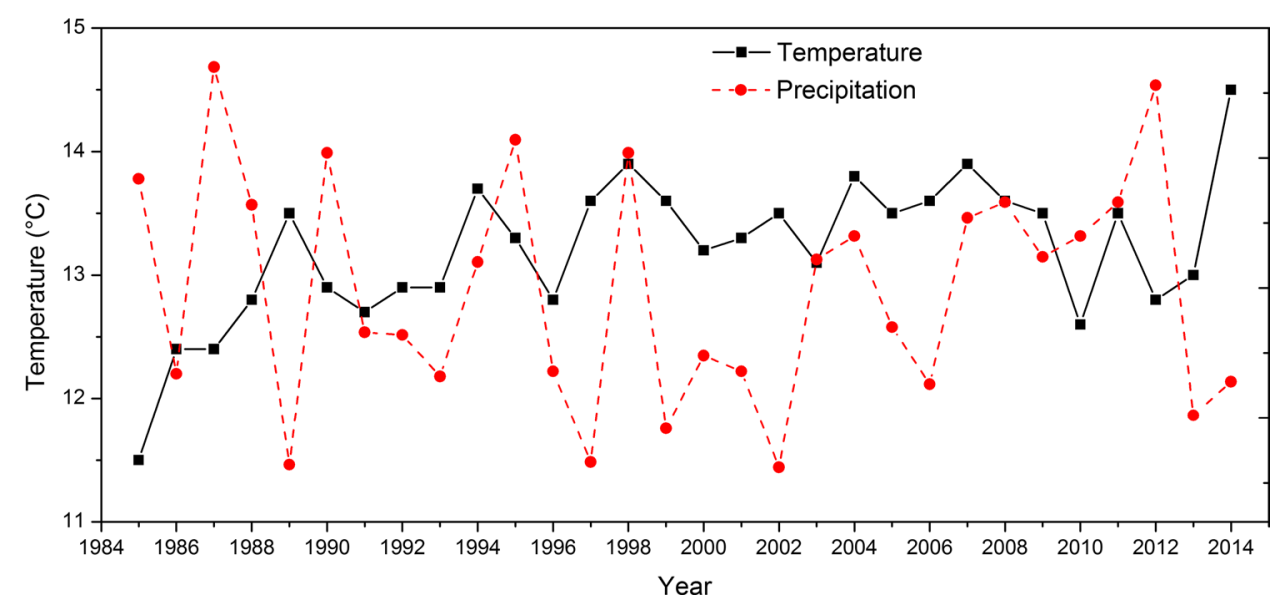

whole study area and water quality of the whole river was primarily Grade III or even higher. The scattered distribution of areas with Grade II water quality existed due to effective environment management including cleaning of the local rivers and clearing up of some polluting industries located around the rivers. According to water quality evaluation, output values for nearly half of Grade
II sampling points were higher than the median value of Grade II, and even the value of one point was close to the critical value between Grade II and Grade III. In other words, the overall water quality of the Haihe river section could be evaluated as inferior Grade III or Grade IV in the Tianjin Binhai New Area. Therefore, we can conclude that the Haihe River was seriously polluted. 
Table 4 Evaluation grading of surface water quality based on GA-BP neural network

\begin{tabular}{llllllll}
\hline Point & 1 & 2 & 3 & 4 & 5 & 6 & 7 \\
\hline Output value & 4.6378 & 4.1827 & 3.4454 & 3.6151 & 2.3603 & 3.8639 \\
Grade & V & IV & III & IV & II & IV & IV \\
\hline Point & 8 & 9 & 10 & 11 & 12 & 13 \\
\hline Output value & 4.0941 & 1.9610 & 3.0909 & 3.2193 & 2.0123 & 1.8511 \\
Grade & IV & II & III & III & II & II & II \\
\hline Point & 15 & 16 & 17 & 18 & 19 & 20 \\
\hline Output value & 3.3197 & 2.7096 & 2.7329 & 1.7462 & 1.5278 & 3.7719 \\
Grade & III & III & III & II & II & IV \\
\hline
\end{tabular}

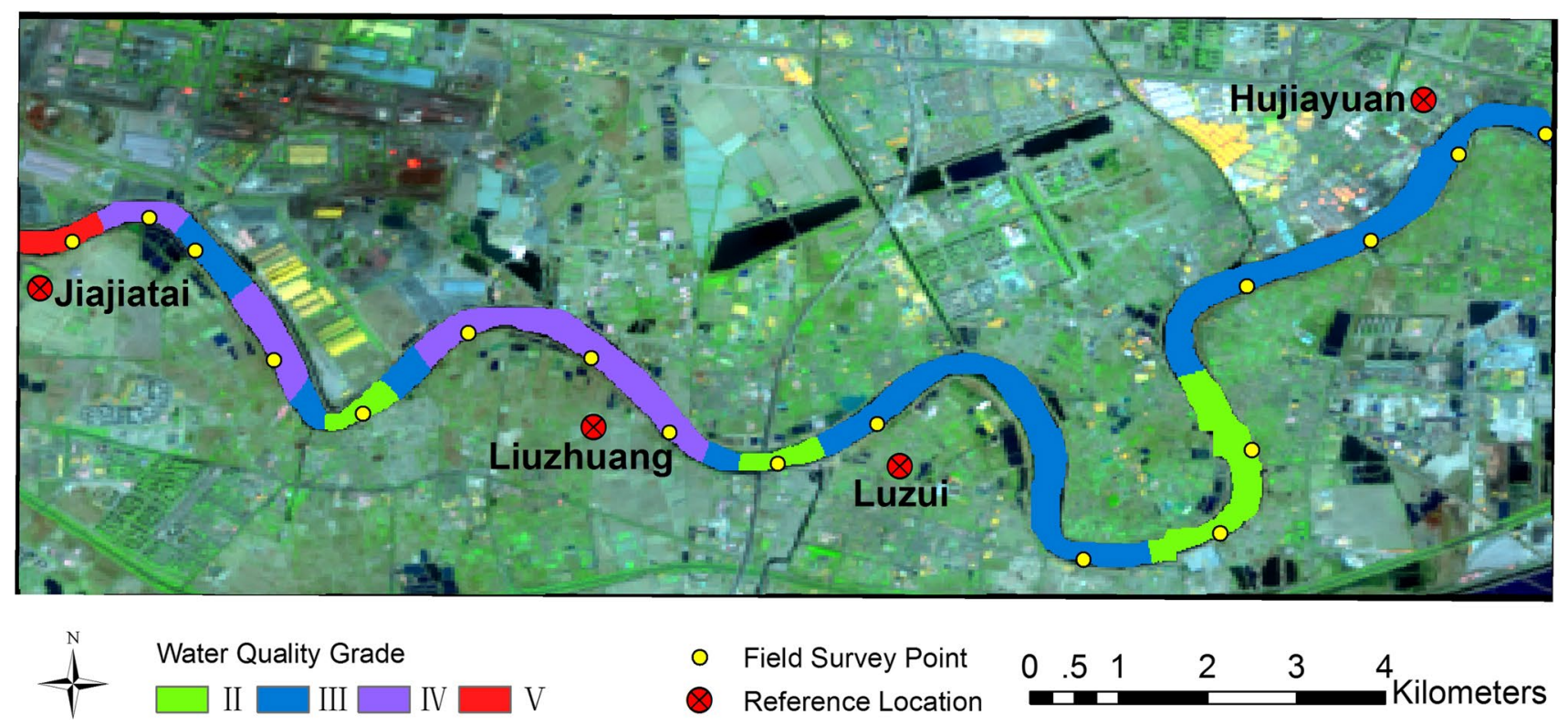

Fig. 6 Partial enlargement map of Kriging interpolation results for the water quality sampling points

\section{Discussion}

\section{Method of water change detection}

To verify reliability of the MNDWI-based adaptive dynamic threshold method used in detecting spatiotemporal change of surface water, surface water extraction results were compared with those using other four methods, including single-band threshold, multi-band spectral relationship, ISODATA and MNDWI. The test area was a part of study area and chosen from TM image in 2005, where waters have a clear border (Fig. 7a). Binaryzation was applied by assigning 1 (white) to water and 0 (black) to background as shown in Fig. 7.

The extraction results were compared using the five methods (Fig. 7b-f). The classification result using single-band threshold incorrectly divided some non-water areas into waters (Fig. 7b). The classification result using multi-band spectral relationship divided an integral water area into waters with lots of non-water patches (Fig. 7c). The classification result using ISODATA omitted a large number of water patches (Fig. 7d). The classification result using MNDWI was not able to differentiate background from waters (Fig. 7e). The classification result using MNDWI-based adaptive dynamic threshold method was better in extracting river, lake and salt evaporation pond (Fig. 7f).

On the basis of extraction results, accuracy analysis was conducted to compare efficiency of the five methods (Table 5). For the proposed MNDWI-based adaptive dynamic threshold method, its overall accuracy and the kappa coefficient were higher than those for the other four methods (Table 5). Thus, the comparison ensured the high 


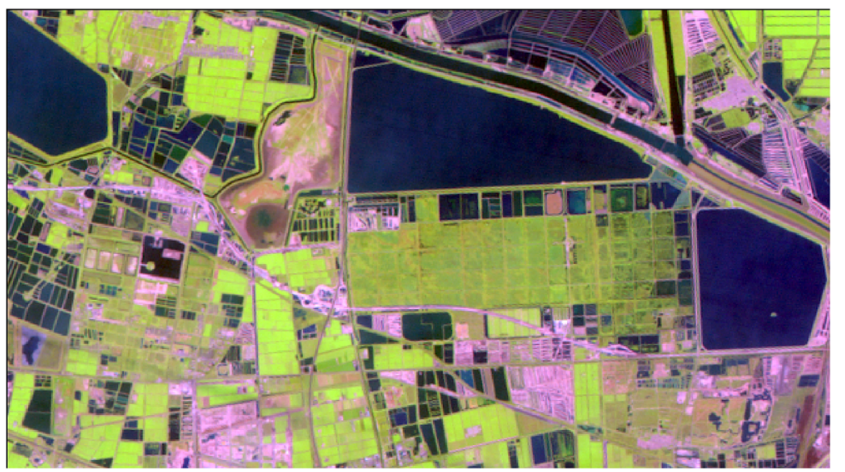

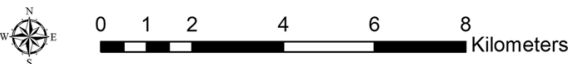

(a)

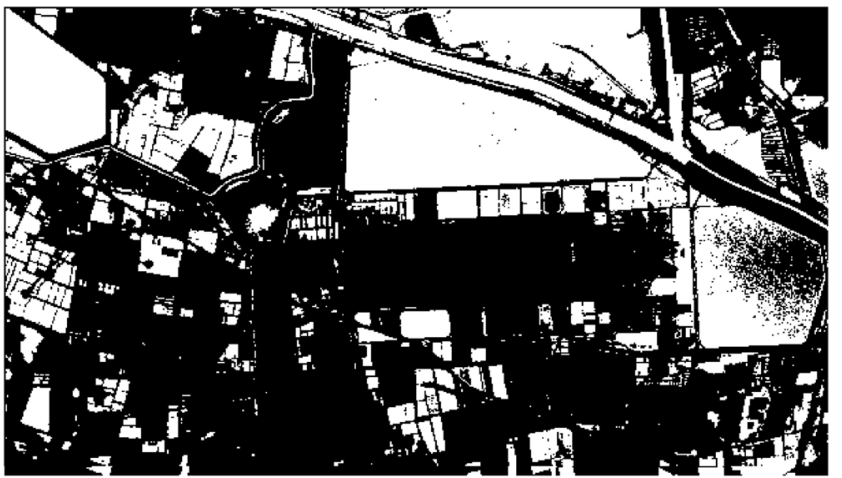

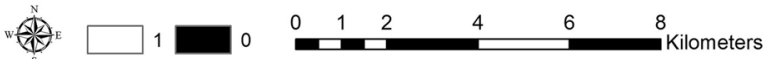

(c)

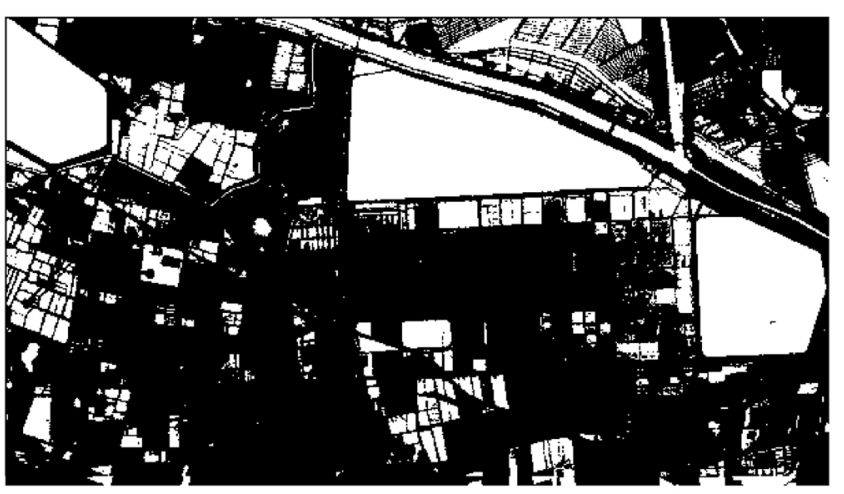

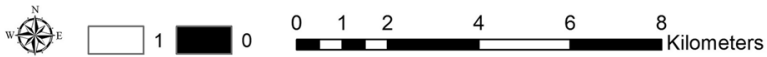

(e)

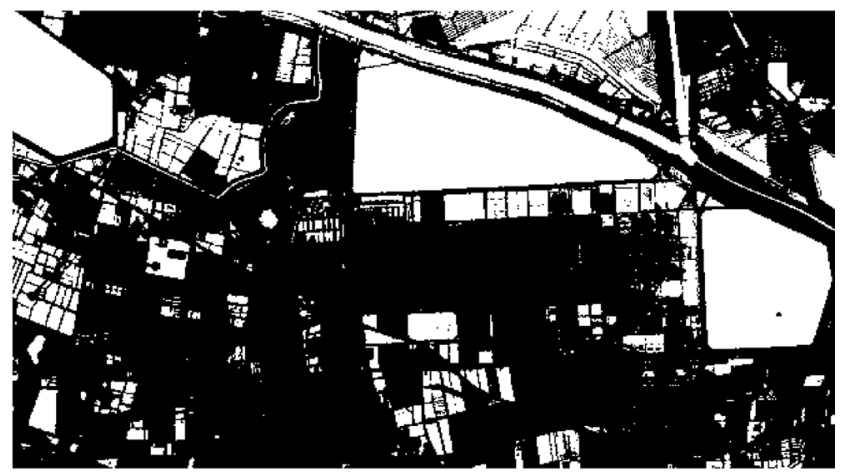

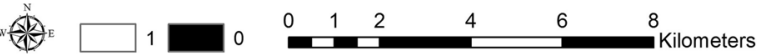

(b)

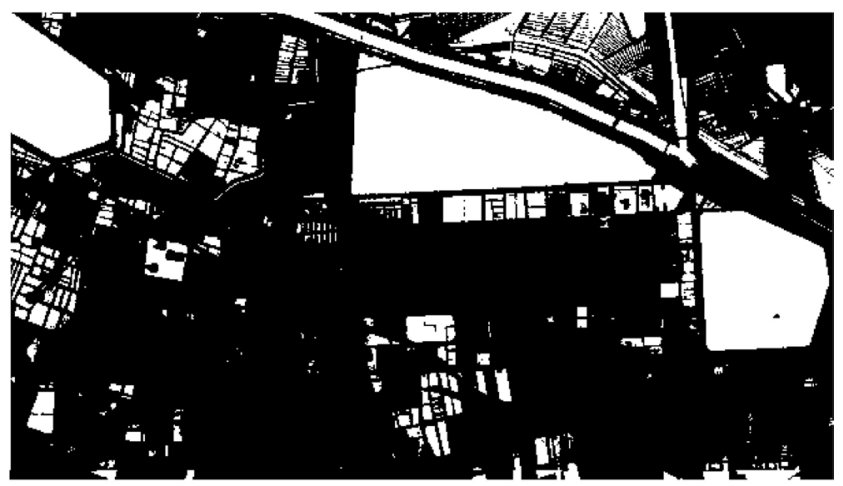

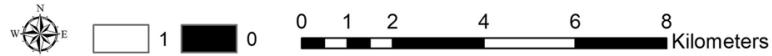

(d)

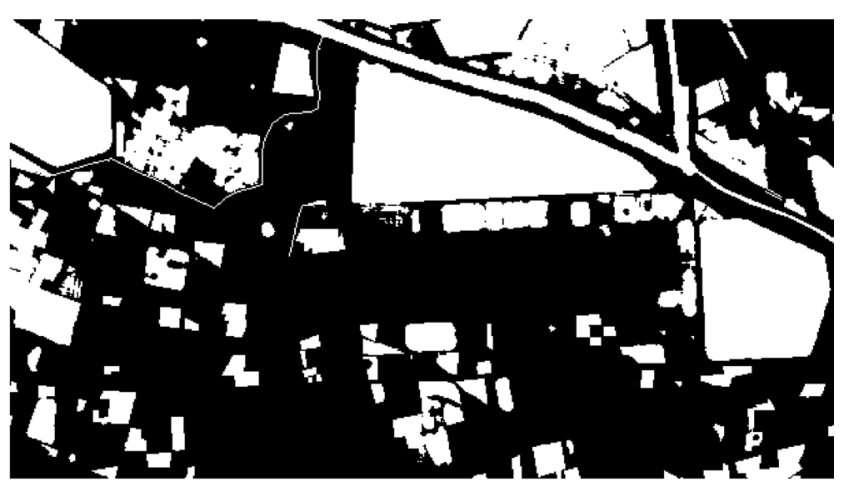

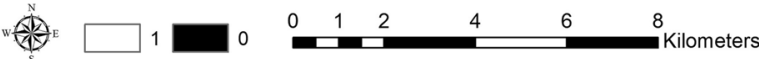

(f)

Fig. 7 Image and water change extraction results of the test area: a TM image; b single-band threshold; c multi-band spectral relationship; d ISODATA; e MNDWI; f MNDWI-based adaptive dynamic threshold

Table 5 Overall accuracy and kappa coefficient of the five methods

\begin{tabular}{lccccl}
\hline Extraction method & $\begin{array}{l}\text { Single-band } \\
\text { threshold }\end{array}$ & $\begin{array}{l}\text { Multi-band spec- } \\
\text { tral relationship }\end{array}$ & ISODATA & MNDWI & $\begin{array}{l}\text { MNDWI-based } \\
\text { adaptive dynamic } \\
\text { threshold }\end{array}$ \\
\hline Overall accuracy & $90.00 \%$ & $92.00 \%$ & $88.00 \%$ & $94.00 \%$ & $98 \%$ \\
Kappa coefficient & 0.7543 & 0.8245 & 0.6921 & 0.8444 & 0.9516 \\
\hline
\end{tabular}


effectiveness of MNDWI-based adaptive dynamic threshold in surface water change detection.

\section{Method of water quality evaluation}

In this study, a new GA-BP neural network was developed in which GA was introduced to optimize initial weight and threshold of BP neural network. It overcame the imperfections of traditional BP neural network, like local extremum and randomness of initial weights and thresholds ( $\mathrm{Yu}$ and $\mathrm{Xu}$ 2014). Tests on the developed GA-BP neural network from some aspects were conducted (Fig. 8).
According to the regression function of neural network training, almost no difference existed between the training output and test output (Fig. 8a). Since the training output data met the national evaluation standard of surface water environment, the test output result was supposed to be accurate. The mean square error and the accuracy were also recorded based on the accuracy performance function (Fig. 8b). Accuracy performance function was used to specifically determine which accuracy the data reach when the network was trained. The whole network reached the optimal accuracy of $9.3898 \mathrm{E}-06$ after three times training. The fitness function curves of BP neural network and

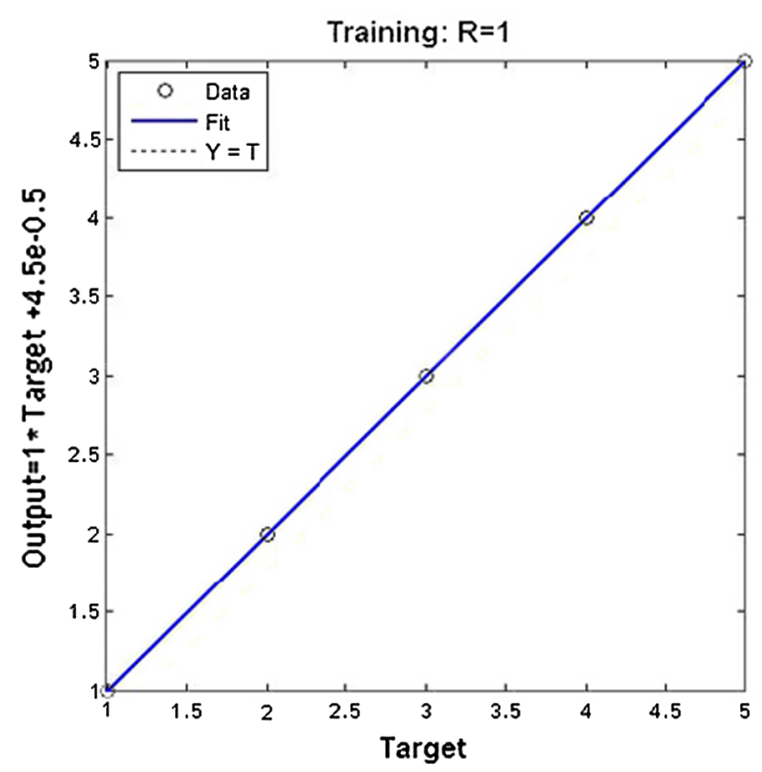

(a)

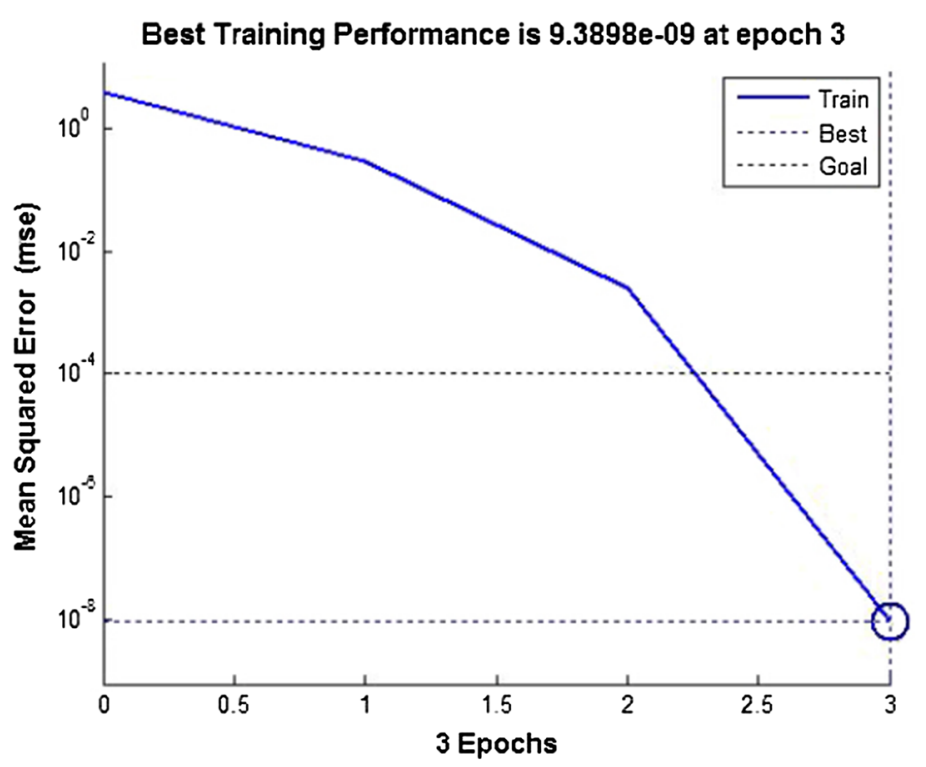

(b)

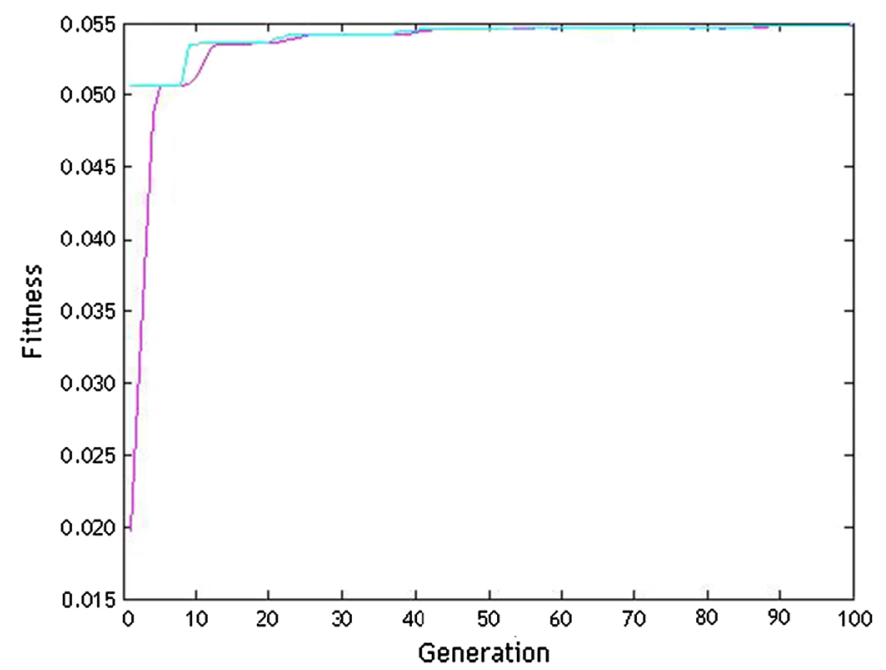

(c)

Fig. 8 Results about GA-BP network: a regression function: $\mathrm{X}$ axis of the regression function is the target accuracy, and $\mathrm{Y}$ axis is the accuracy of network training; $\mathbf{b}$ the accuracy performance function:
$\mathrm{X}$ axis is the training epoch, and $\mathrm{Y}$ axis is the mean squared error; $\mathrm{c}$ fitness function curves: red line for BP neural network algorithm and blue line for GA-BP neural network algorithm 
GA-BP neural network showed that weight and threshold selection of BP neural network optimized by GA was advantageous over that of single BP neural network. The greater the fitness function value, the faster the algorithm converges and the faster the computing speed. The computing speed of GA-BP network was greatly improved under the same condition (Fig. 8c).

On the basis of test input data and test output data for the GA-BP neural network, a correlation analysis was conducted. The analysis result showed that optimized fitting coefficient of both data was 0.928 , which indicated a good correlation existed between test data of GA-BP neural network. The tests ensured high effectiveness and reliability of GA-BP neural network in surface water evaluation.

In a word, these two methods - the MNDWI-based adaptive dynamic threshold method and the GA-BP neural network method-have high precision in monitoring surface water change and evaluating water quality; therefore, they can be extended to study on water environment assessment in other study areas.

\section{Impact analysis of surface water dynamic change}

In this study, only four factors affecting water change were analyzed including temperature, precipitation, population and GDP. Some other factors like the total real estate investment may also have influence on water quality. Therefore, more factors should be considered for comprehensive causing analysis of spatiotemporal water change in future.

\section{Implication to practical management}

Although local government has made great efforts to protect freshwater resources, the current shortage of freshwater resources is still severe. There are some suggestions on practical management. For citizens, it should promote publicity education on water conservation awareness and practices. For companies, it should encourage application of new energy desalination such as wave energy. For local government, it should strengthen investment in both funding and professional personnel to execute management.

\section{Conclusions}

This study focused on surface water change and evaluation of water quality in the Tianjin Binhai New Area, using seven scenes of Landsat remote sensing images during 1985-2014. In this study, the MNDWI-based adaptive dynamic threshold method was proposed to detect water change. Compared with other four water extraction methods-single-band threshold, multi-band spectral relationship, ISODATA and MNDWI method, the MNDWI-based adaptive dynamic threshold method was proved to perform better. And a new GA-BP neural network was developed to do environment evaluation of water quality. The test proved that BP neural network had improvement in varying degree on both convergence speed and accuracy of training. It reduced occurrence frequency of local extremum greatly during the network training. Both proposed methods were proved to be reliable and worth promoting to similar study in other study areas.

The types of land use in the Tianjin Binhai New Area included land, river, lake, salt evaporation pond and seawater. Change of water area in seven periods was derived using the MNDWI with adaptive dynamic threshold. According to analysis of water area change in the Tianjin Binhai New Area, the water area in the Tianjin Binhai New Area have experienced up and down process in recent almost 30 years. The area of lake and river was fluctuating from 1985 to 2014 and eventually increased. Seawater area had decreased since 1990. Temperature and precipitation brought positive impact on water change. Besides, population and economic development also played a positive role in the expansion of freshwater area and shrinking of salty water area. The impact of climatic factors and human activity contributed to the present water environment situation.

According to distribution of water quality grade for the Haihe River section in study area, water quality of the Haihe River was poor in Tianjin Binhai New Area as a whole, and water quality grade was mostly clustered above Grade III. Particularly, water quality was mainly for Grades IV and V from Jiajiatai to Liuzhuang River section and situation of water quality was very bad. Residential and industrial lands were densely distributed along the river. If the management measures were not timely or improper, the normal production and living of local residents may be affected. Moreover, it may cause a vicious circle of interactional effect between human living environment and river water quality situation. Based on water quality analysis, some suggestions were proposed for practical management to encounter shortage of freshwater resource in the study area.

Acknowledgements This work was financially supported by the Natural Science Foundation of Tianjin, China (Grant No. 18JCYBJC90900) and the Scientific Research Project of Tianjin municipal Education Commission, China (Grant No. 2018KJ164).

Author contributions Qiaozhen Guo had the original idea for the study. Xiaoxu Wu, Xiao Sang and Ying Fu were responsible for data collection and processing. The model results were analyzed by Yuchen Zang and Xuemei Gong. All authors drafted the manuscript and have read and approved the final version.

\section{Compliance with ethical standards}

Conflict of interest The authors declare no conflict of interest. 
Open Access This article is distributed under the terms of the Creative Commons Attribution 4.0 International License (http://creativeco mmons.org/licenses/by/4.0/), which permits unrestricted use, distribution, and reproduction in any medium, provided you give appropriate credit to the original author(s) and the source, provide a link to the Creative Commons license, and indicate if changes were made.

\section{References}

An Y, Zou ZH, Li RR (2014) Water quality assessment in the Harbin Reach of the Songhuajiang River (China) based on a fuzzy rough set and an attribute recognition theoretical model. Int J Environ Res Publ Health 11:3507-3520. https://doi.org/10.3390/ijerp h110403507

Bukata RP (2013) Retrospection and introspection on remote sensing of inland water quality: like Déjà Vu all over again. J Great Lakes Res 39:2-5. https://doi.org/10.1016/j.jglr.2013.04.001

Chen J, Quan W, Wen Z, Cui T (2013) An improved three-band semianalytical algorithm for estimating chlorophyll-a concentration in highly turbid coastal waters: a case study of the Yellow River estuary, China. Environ Earth Sci 69:2709-2719. https://doi. org/10.1007/s12665-012-2093-1

Chow MF, Shiah FK, Lai CC, Kuo HY, Wang KW, Lin CH, Chen TY, Kobayashi Y, Ko CY (2016) Evaluation of surface water quality using multivariate statistical techniques: a case study of Fei-Tsui Reservoir basin, Taiwan. Environ Earth Sci 75:6-20. https://doi. org/10.1007/s12665-015-4922-5

Essam SED, Zhang Y, Alaeldin S (2017) Mapping concentrations of surface water quality parameters using a novel remote sensing and artificial intelligence framework. Int J Remote Sens 38:10231042. https://doi.org/10.1080/01431161.2016.1275056

Li W, Du Z, Ling F, Zhou D, Wang H, Gui Y, Sun B, Zhang X (2013) A comparison of land surface water mapping using the normalized difference water index from TM, ETM + and OLI. Remote Sens 5:5530-5549. https://doi.org/10.3390/rs5115530

McFeeters SK (2013) Using the normalized difference water index (NDWI) within a geographic information system to detect swimming pools for mosquito abatement: a practical approach. Remote Sens 5:3544-3561. https://doi.org/10.3390/rs5073544
Meng X, Zhang Y, Yu X, Zhan JY, Chai YY, Critto A, Li YT, Li JJ (2015) Analysis of the temporal and spatial distribution of lake and reservoir water quality in china and changes in its relationship with GDP from 2005 to 2010. Sustainability 7:2000-2027. https ://doi.org/10.3390/su7022000

Nechad B, Ruddick KG, Park Y (2010) Calibration and validation of a generic multisensor algorithm for mapping of total suspended matter in turbid waters. Remote Sens Environ 114:854-866. https ://doi.org/10.1016/j.rse.2009.11.022

Palmer SJ, Kutser T, Peter DH (2015) Remote sensing of inland waters: challenges, progress and future directions. Remote Sens Environ 157:1-8. https://doi.org/10.1016/j.rse.2014.09.021

Park Y, Cho KH, Park J (2015) Development of early-warning protocol for predicting chlorophyll-a concentration using machine learning models in freshwater and estuarine reservoirs, Korea. Sci Total Environ 502:31-41. https://doi.org/10.1016/j.scito tenv.2014.09.005

Perrin JL, Raïs N, Chahinian N, Moulin P, Ijjaali M (2014) Water quality assessment of highly polluted rivers in a semi-arid Mediterranean zone Oued Fez and Sebou River (Morocco). J Hydrol 510:26-34. https://doi.org/10.1016/j.jhydrol.2013.12.002

Rokni K, Ahmad A, Selamat A, Haini S (2014) Water feature extraction and change detection using multitemporal Landsat imagery. Remote Sens 6:4173-4189. https://doi.org/10.3390/rs6054173

Sun F, Sun W, Chen J, Gong P (2012) Comparison and improvement of methods for identifying water bodies in remotely sensed imagery. Int J Remote Sens 33:6854-6875. https://doi.org/10.1080/01431 161.2012.692829

Xu HQ (2006) Modification of normalised difference water index (NDWI) to enhance open water features in remotely sensed imagery. Int J Remote Sens 27:3025-3033. https://doi. org/10.1080/01431160600589179

Yu F, Xu XZ (2014) A short-term load forecasting model of natural gas based on optimized genetic algorithm and improved BP neural network. Appl Energy 134:102-113. https://doi.org/10.1016/j. apenergy.2014.07.104

Publisher's Note Springer Nature remains neutral with regard to jurisdictional claims in published maps and institutional affiliations. 